\title{
دراسة تقييميه لأثر الأزمة المالية العالمية على أداء البنوك الإسلامية حالة بنك البركة الجزائري والبنك الأردني الإسلامي (2006-2011)
}

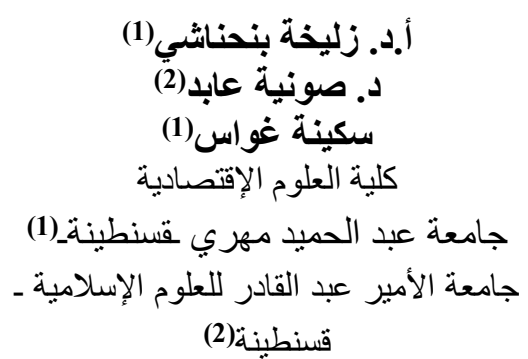

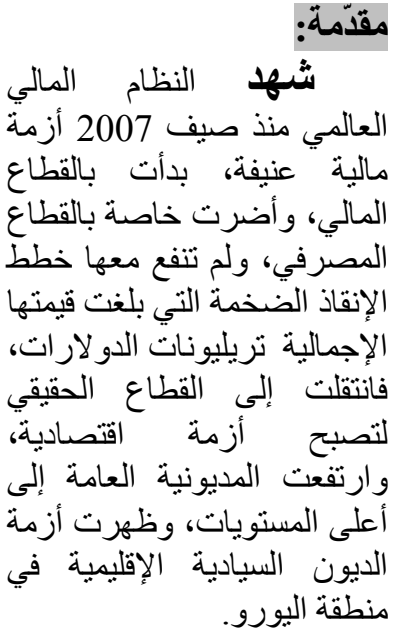

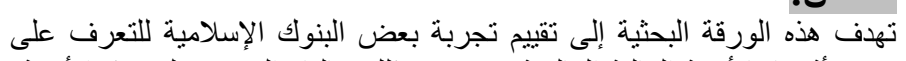

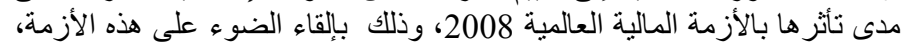
حيث بدأت في صيف

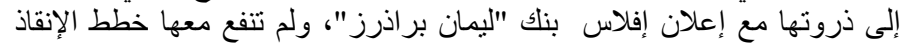

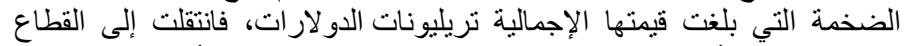

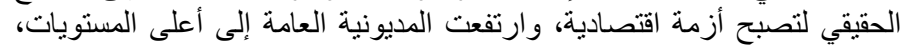

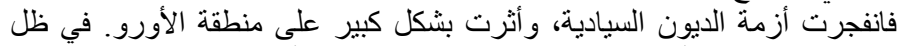

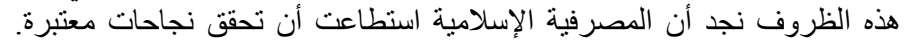

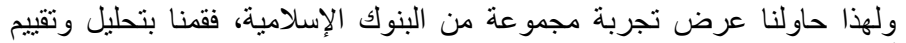

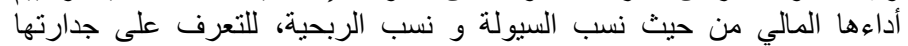

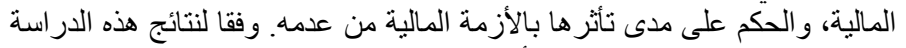

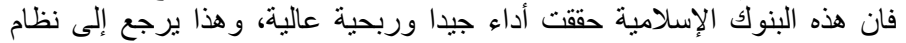

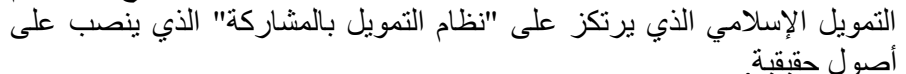

$$
\text { الأداء، الربحية، المفتاحية: البنوك الإسلامية، الأزمة المالية العالمية، مؤشرات }
$$

\begin{abstract}
:
The purpose of this article is to explain the global financial crisis of 2008. This crisis began in the summer of 2007, very violently, it affected the financial sector, and reached its peak at the announcement of the bankruptcy of the bank "Lehman Brothers". Despite several bailouts costing several trillion dollars, this crisis has turned into an economic crisis. Public debt has risen to reach higher levels, which has led to the explosion of the sovereign debt crisis and has affected the euro area to a large extent.

In the same conditions, we found that the Islamic banking sector has managed to achieve considerable success. That's why we tried to present the experience of a group of Islamic banks

We analyzed and evaluated their financial performance in terms of liquidity ratios and profitability ratios in order to know and see if they were affected by the global financial crisis. According to the results of this study, these Islamic banks have made high profits this thanks to the Islamic financial system that is based on the
\end{abstract} crowdfunding system that focuses on real assets.

KEY WORDS: Global financial crisis, Islamic banks, performance of Islamic banks, profitability, liquidity, 


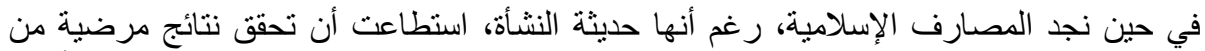

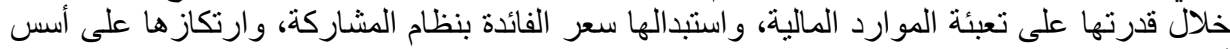

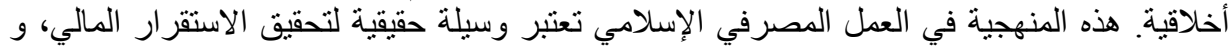

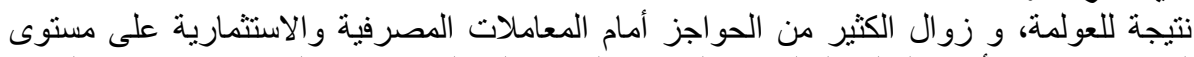

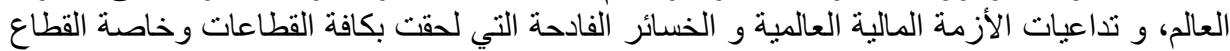

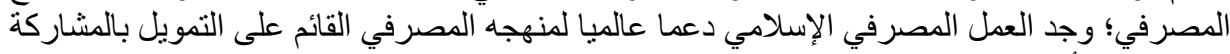

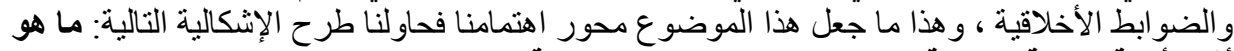

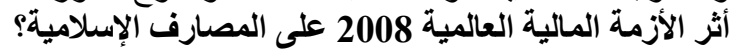

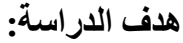

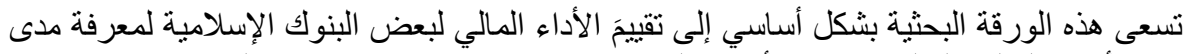

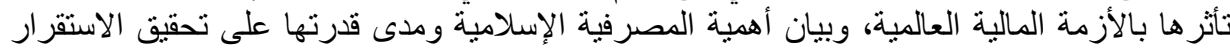

الفرضية الأولى: الأسباب الرئيسية لاندلاع الأزمة المالية العالمية هي: التعامل بالربا وبيع الديون

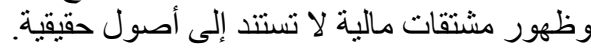

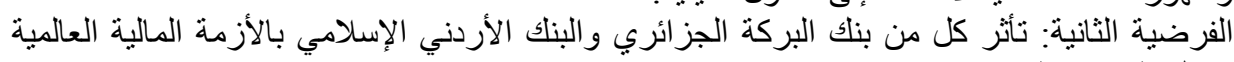
بشكل طفيف فقط. منهجية الاراسة: تتبع الدراسة المنهج الوصفي التحليلي في الجانب النظري عند تحليل الأزمة المالية العالمية وكنللك الإلئ

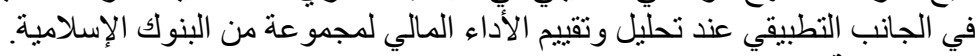

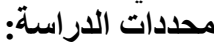
تتتاول هذه الدراسة تحليل وتقيبم المركز المالي لبنكا البركة الجزائري والبنك الأردني الإسلامي

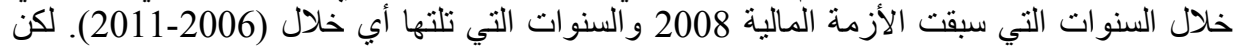

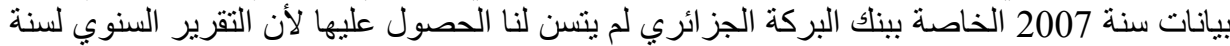

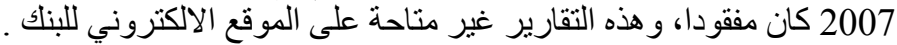

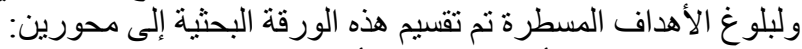

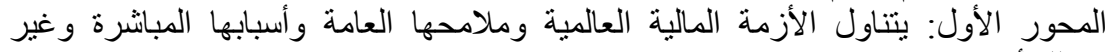

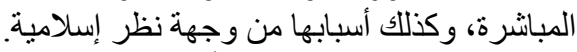

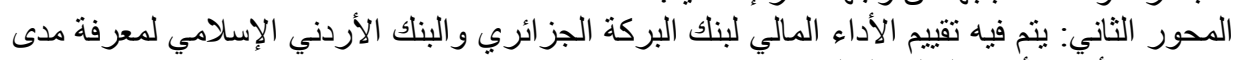
صمودهما أمام الأزمة المالية العالمية.

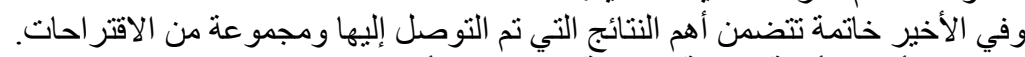

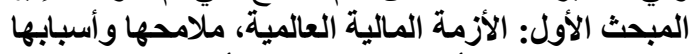

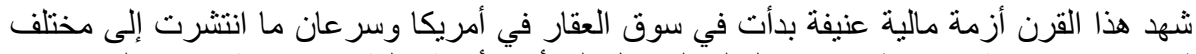

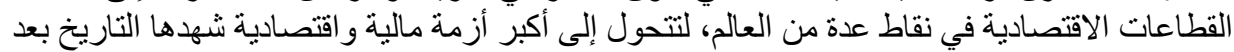
أزمة الكساد الكبير لسنة 1929، ولا لانز الكال عدة دول من العالم تعاني من آثار ها وتداعياتها حتى الساعة.

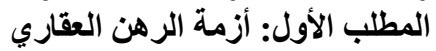

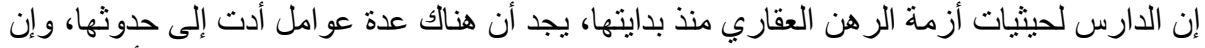

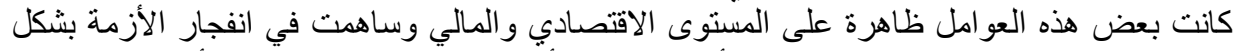

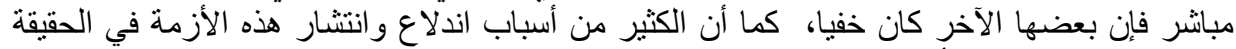
مرتبط بطبيعة النظام الر أسمالي الربوي نفسان. 
وللتفصيل في أسباب الأزمة، بمكن تقسيمها إلى ثلاثة أقسام: أسباب مباثرة و أسباب غير مبانشرة، و أسباب أخرى من رؤية إسلامية. أولا: الأسباب المباشرة لأزمة الرهن العنابة العقاري:

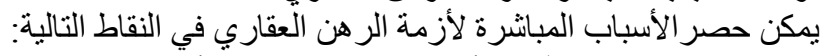

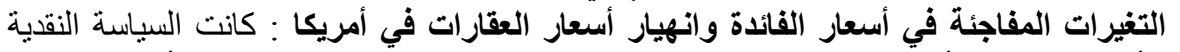

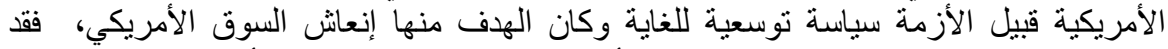

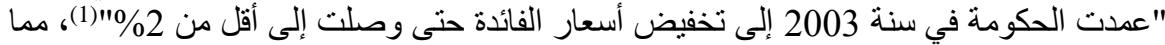

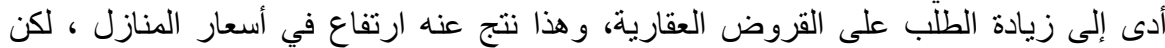

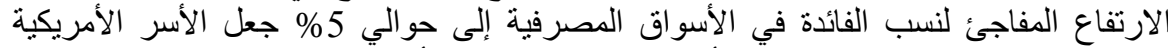

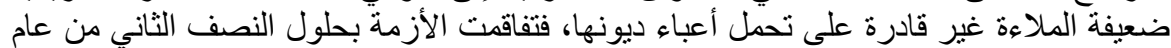

الرهون العقارية الأقل جودة: وهي رهون ناتجة عن رهن العقار مرة ثانية، حيث أن المواطن

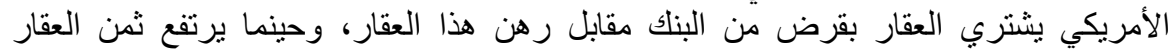

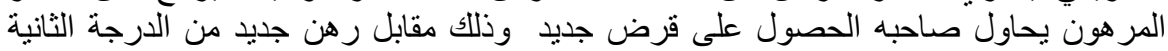

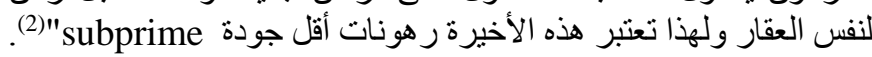

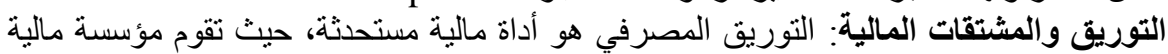

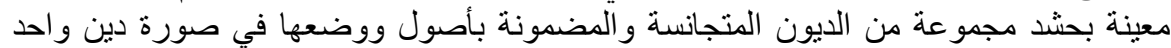

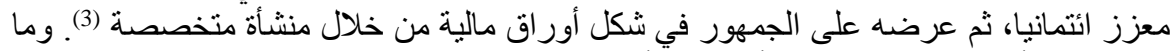

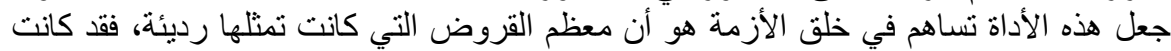

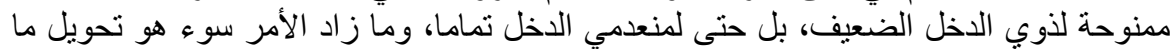

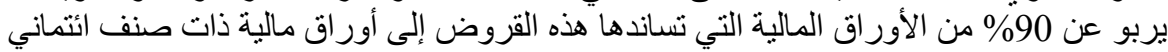

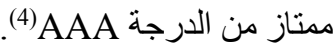

ـ ثنانيا: الأسباب غير المباشرة للازمة المالية:

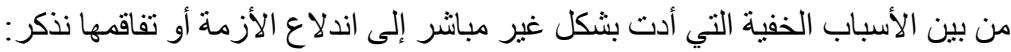

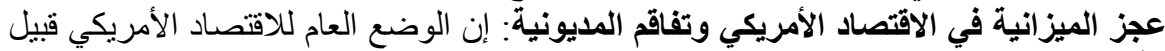

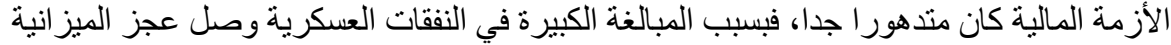

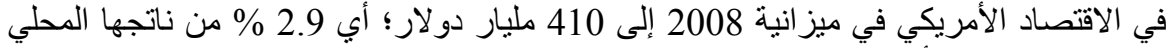

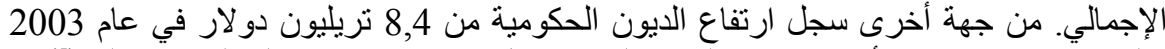

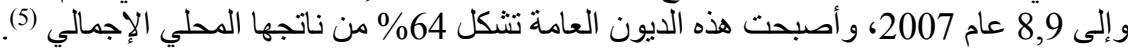

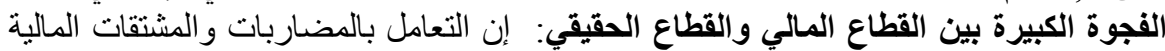

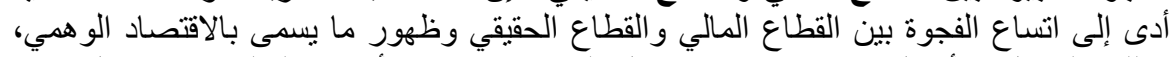

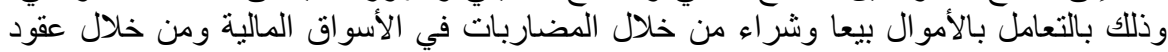

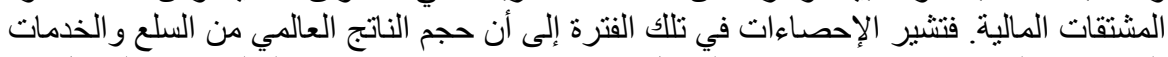

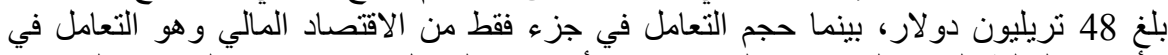

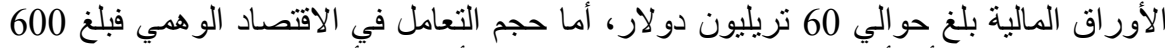

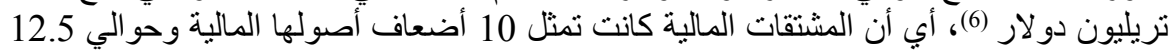


المالية ترجع إلى طبيعة النظام الرأسمالي وجانبه المالي المعقد، فالقطاع المالي في النظام الرأسمالي

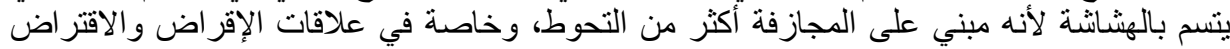

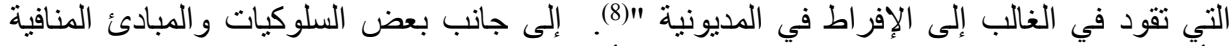

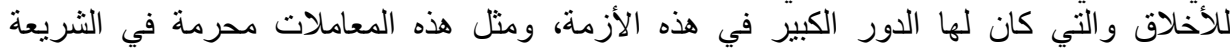

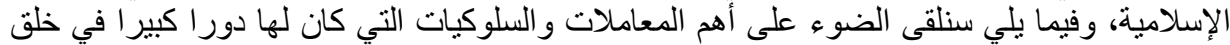
وتفاقم هذه الأزمة من منظور الثريعة الإسلامية:

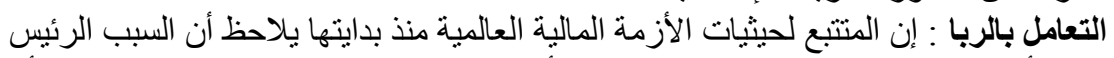

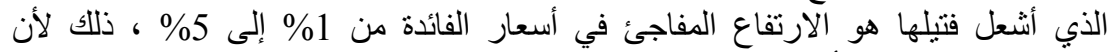

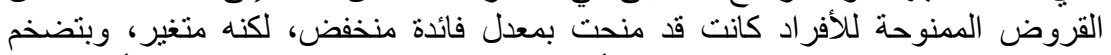

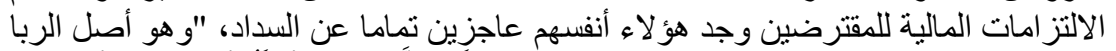

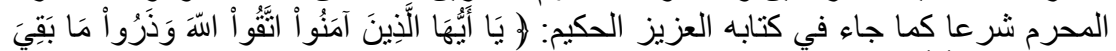

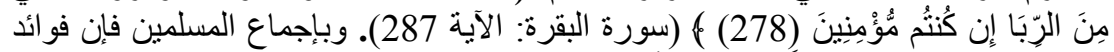

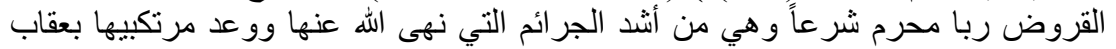

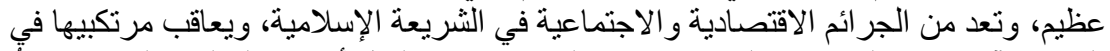

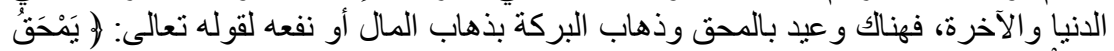

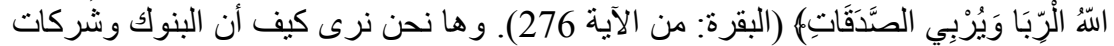

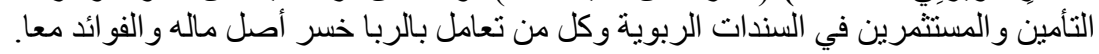

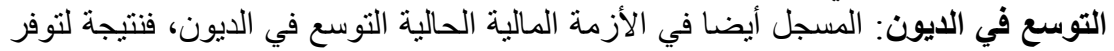

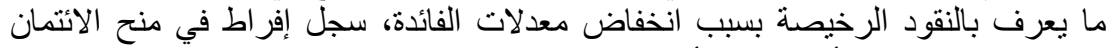

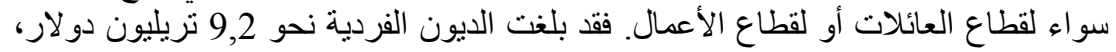

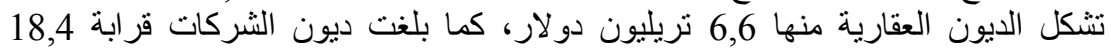

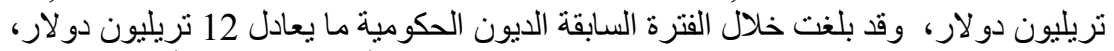

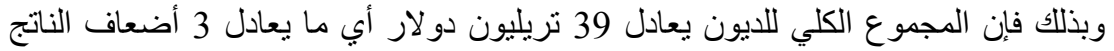

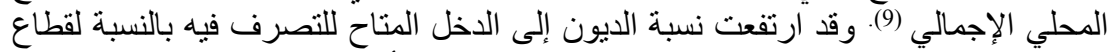

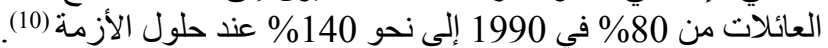

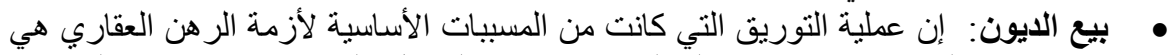

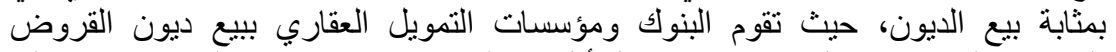

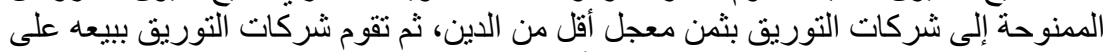

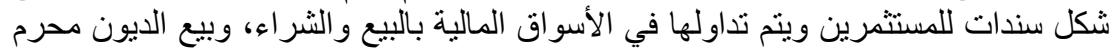

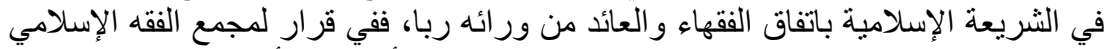

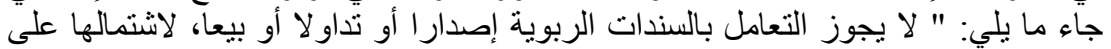

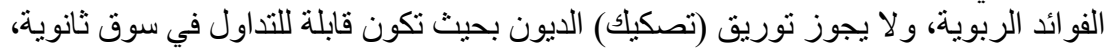

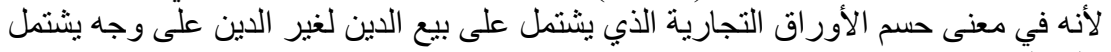

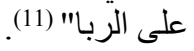

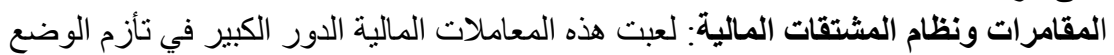

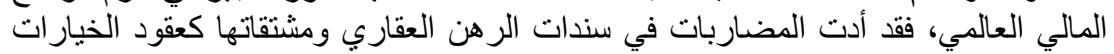

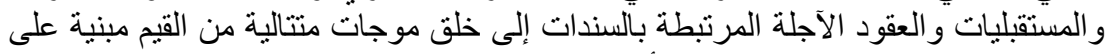

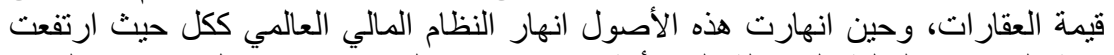

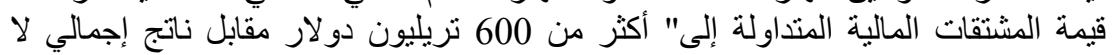

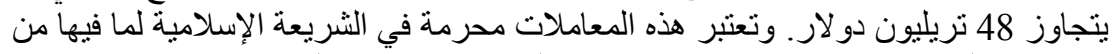

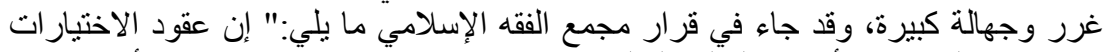
كما تجرى اليوم في الأسواق المألية العالمية هي عقود مستحدثة، لا لتنطوي تحت الي الي عقد من الإن 
العقود الثرعية المسماة، وبما أن المعقود عليه لبس مالا و لا منفعة و لا حقا مالبا يجوز

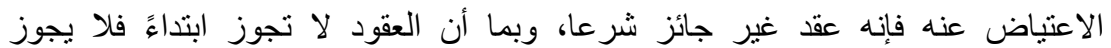

إن هذه التجاوزات والانحر افات في المعاملات المالية والمتمثلة في التعامل بالربا والمضاربات

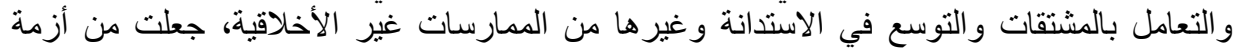

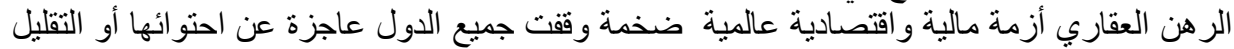

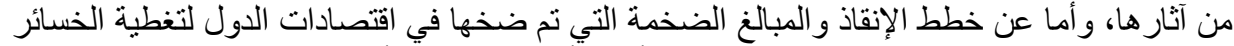

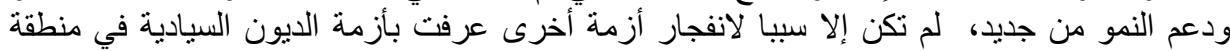

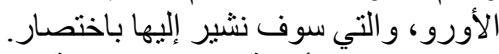

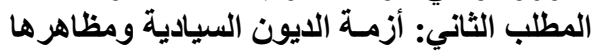

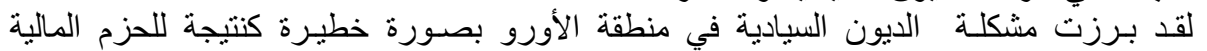

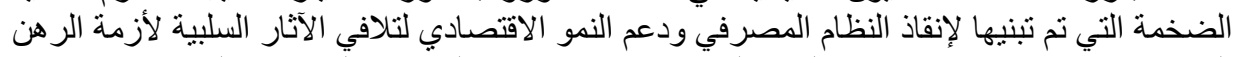

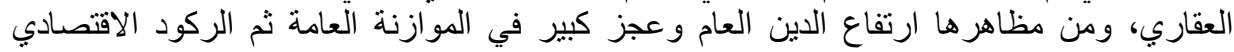

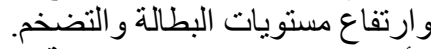

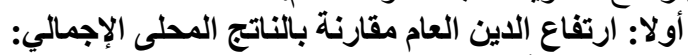

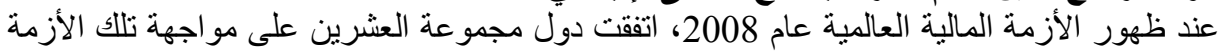

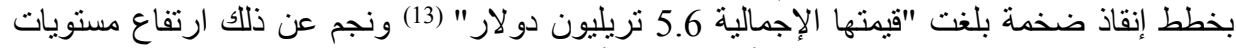

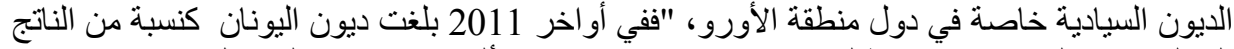

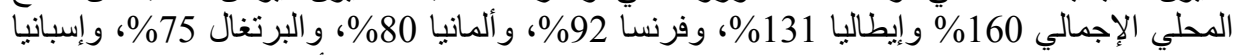

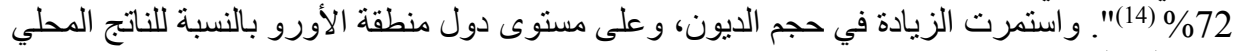

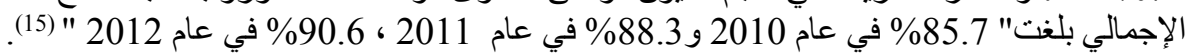

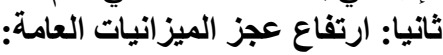

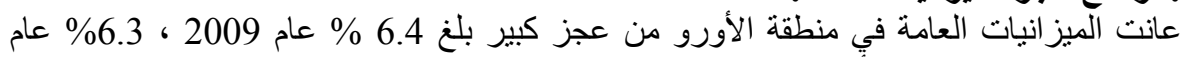

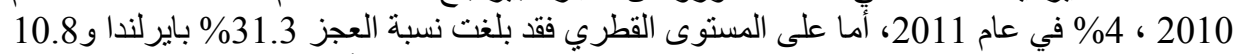

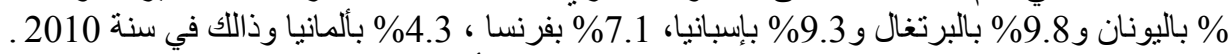

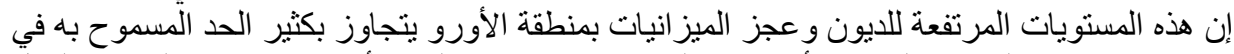

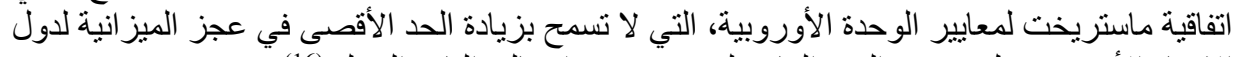

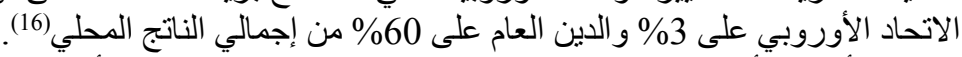

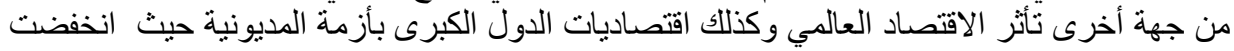

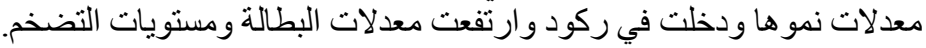
ثنالثا: الركود الاقتصادي

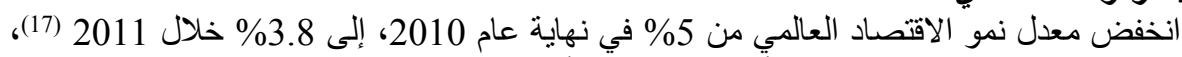

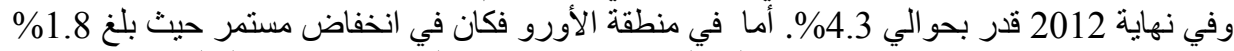
61.6\% في عامي 2010 و 2011 (18) على ألترتيب. ويعد تباطؤ النمو الاقتصادي العالمي سبياً ونتيجة في نفس الوقت لازمة الديون السيادية.

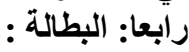

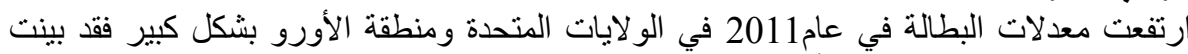

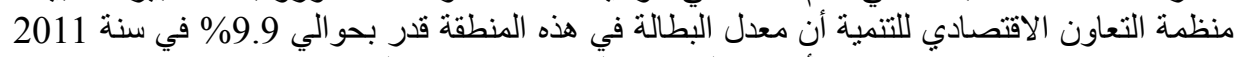
بعدما كان 8\% في ديسمبر 2008 أما في الو لايات التيحدة فقد ارتفع إلى بـ 9.9\% في عام 2011 بعدما 
كان 7.6\% في جانفي 2009 ـوحسب الديوان الأوربي للإحصاء فقد بلغ عدد العاطلين عن العمل في الإنى

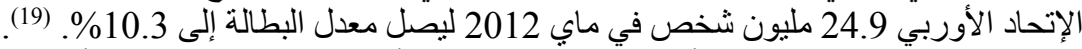

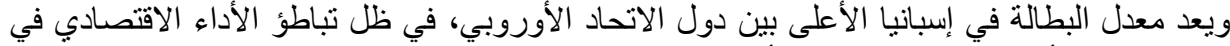

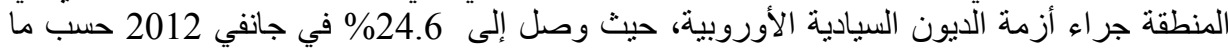
أوضحه تقرير للمعهد الوطني الإسباني للإحصاء (20)

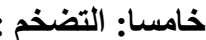

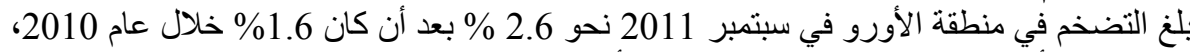

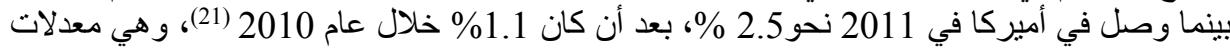

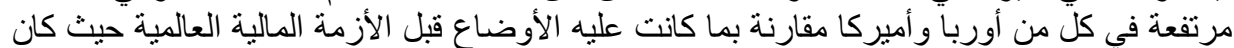

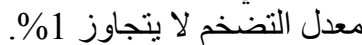
إن هذه الأوضاع الاقتصادية التي كانت تتخبط فيها معظم دول العالم وبمستويات مختلفة، والآثار

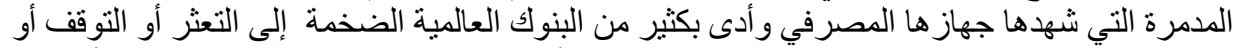

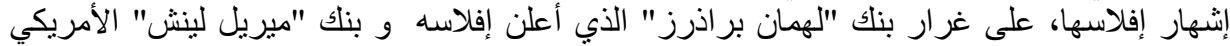

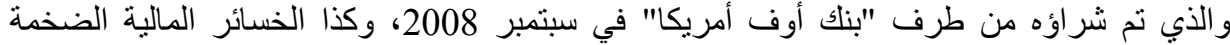

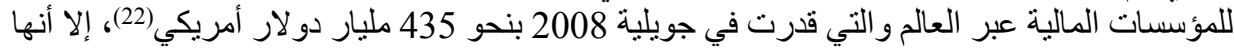

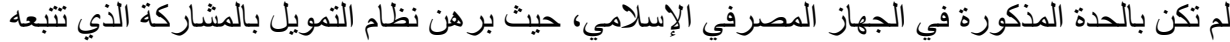

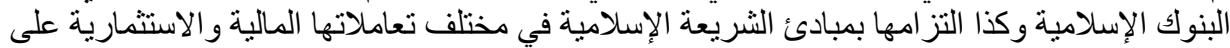

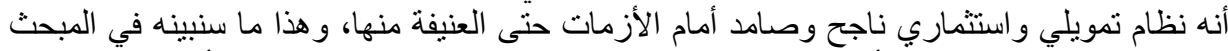

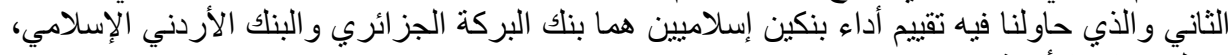

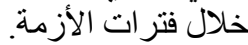
المبحث الثاني: تقييم الأداء المالي لبتك البركة الجزائري والبنك الأردني الإسلامي

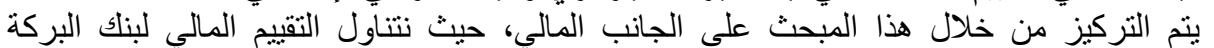

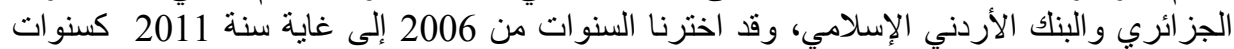

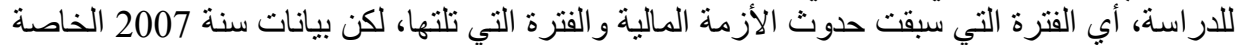

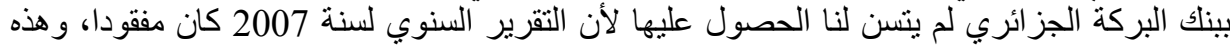

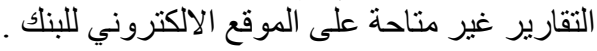

المطلب الأول: تقييم الأداء المالي لبنك البركة الجزائري

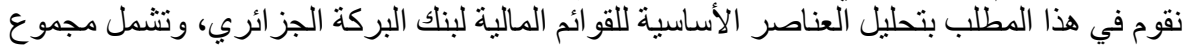

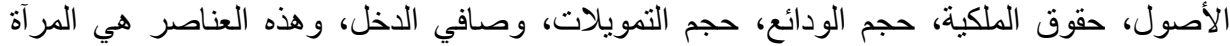

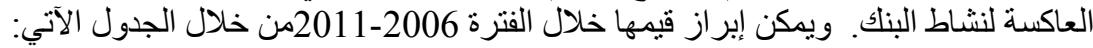


دراسة تقييميه لأثز الأزمة المالية العالمية على أداء البنوك الإسلامية

حالة بنك البركة الجزائري والبنك الأردني الإسلامي (2006-2011)

الجدول رقم (1):بيان لأهم المعلومات المالية لبنك البركة الجز ائري خلال الفترة (2006-1 2012)

\begin{tabular}{|c|c|c|c|c|c|}
\hline \multicolumn{6}{|c|}{ الوحدة:مليون د.ج } \\
\hline 2011 & 2010 & 2009 & 2008 & 2006 & البيان \\
\hline 132984 & 120509 & 98845 & 72254 & 45969 & مجموع الأصول \\
\hline 20550 & 18843 & 13456 & 6416 & 3828 & حقوق الملكية \\
\hline 103285 & 89983 & 57309 & 39748 & 36531 & جم الودائع \\
\hline 58584 & 55689 & 54874 & 48662 & 29717 & حجم التمويلات \\
\hline 3778 & 3243 & 2854 & 2672 & 1032 & سافي الدخل \\
\hline
\end{tabular}

المصدر : من إعداد الباحثات بالاعتماد على التقارير السنوية لبنك البركة الجز ائري(23)

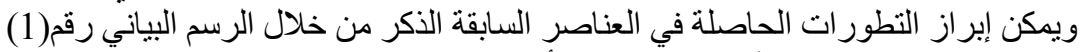

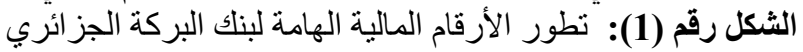

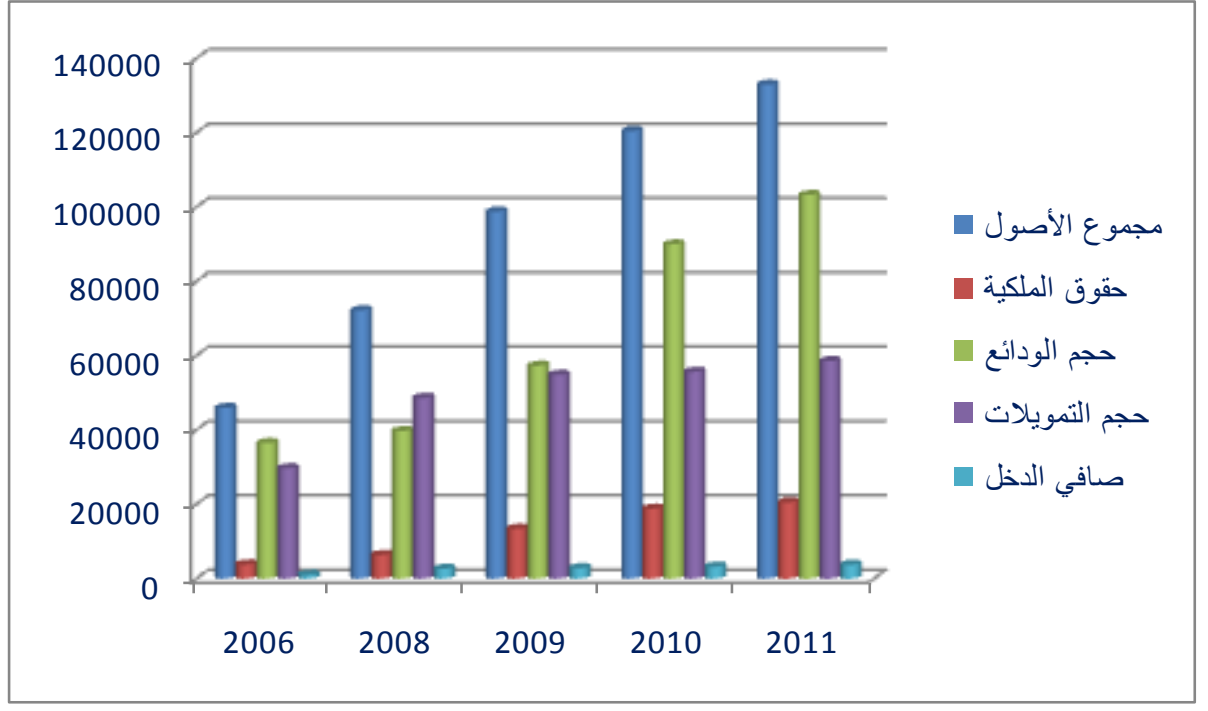

المصدر : من إعداد الباحثات بالاعتماد على الجدول رقم (1)

من خلال الرسم البياني أعلاه نلاحظ أن هناك زيادة مستمرة بالنسبة لجميع العناصر وفي كل

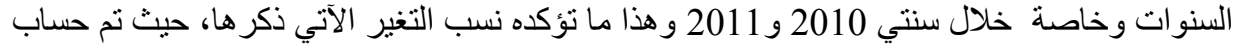


نسب التغير بالنسبة لجميع العناصر وذللك باعتماد سنة 2006 كسنة أساس و السنوات الأخرى كسنوات

الجدول رقم (2): التحليل الأفقي لأهم المعلومات المالية لبنك البركة الجزائر 2011/2006

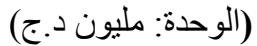

\begin{tabular}{|c|c|c|c|c|c|}
\hline 2011 & 2010 & 2009 & 2008 & 2006 & البيان \\
\hline$\% 189$ & $\% 162$ & $\% 115$ & $\% 57$ & 45969 & مجمو ع الأصول \\
\hline$\% 436$ & $\% 392$ & $\% 251$ & $\% 68$ & 3828 & حقوق الملكية \\
\hline$\% 182.7$ & $\% 146$ & $\% 57$ & $\% 9$ & 36531 & حجم الودائع \\
\hline$\% 97$ & $\% 87$ & $\% 85$ & $\% 64$ & 29717 & حجم التمويلات \\
\hline$\% 266$ & $\% 214$ & $\% 177$ & $\% 159$ & 1032 & صافي الدخل \\
\hline
\end{tabular}

المصدر : من إعداد الباحثات بالاعتماد على التقارير السنوية لبنك البركة الجز ائري

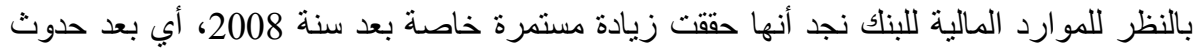

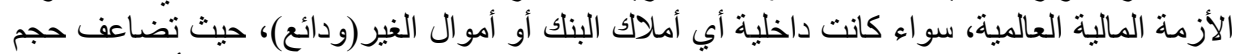

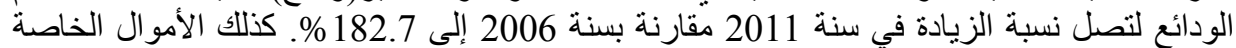

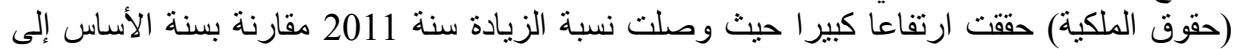

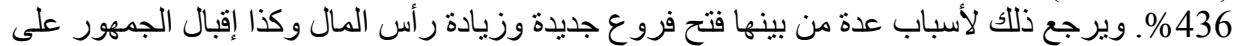

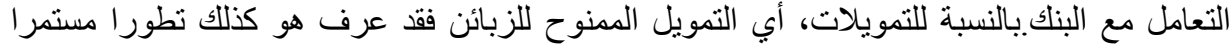

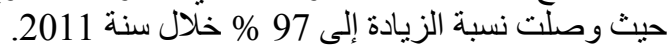

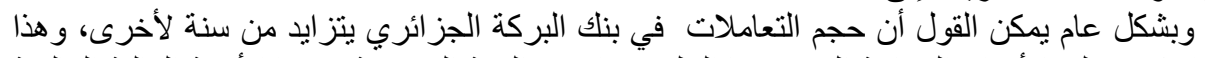

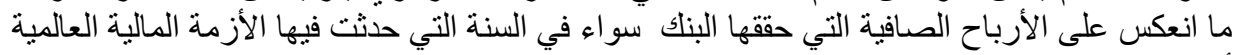

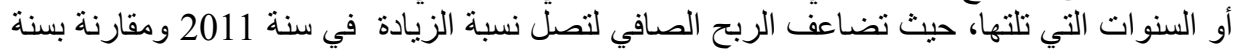

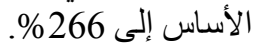

أولا: استخدام النسب المالية في تقييم الأداء المالي لبنك البركة الجزائري:

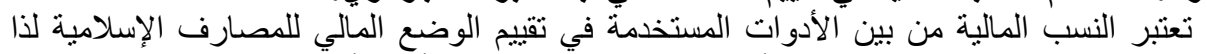

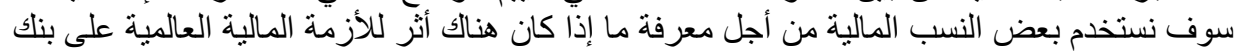

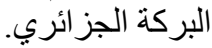

نسب ألسيولة: تقيس نسب السيولة ددى قدرة البنك على الوفاء بالتزاماته النقدية، وذلك إلك

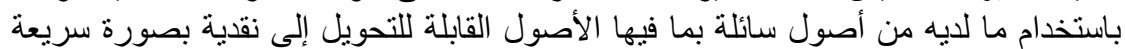

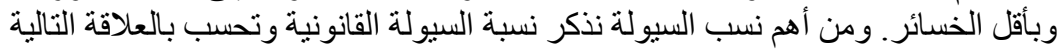

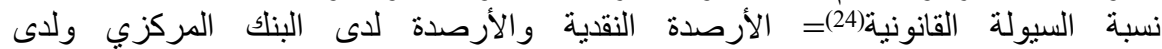

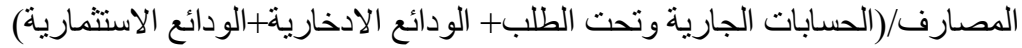

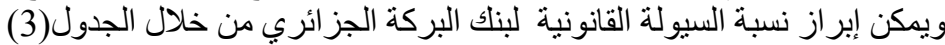
الجدول رقم (3):نسبة السيولة القانونية لدى بتلك البركة الجز الئري ائري خلال 2011/2006

\begin{tabular}{|c|c|c|c|c|c|}
\hline 2011 & 2010 & 2009 & 2008 & 2006 & البيان \\
\hline$\% 91.93$ & $\% 86.87$ & $\% 58.86$ & $\% 32.5$ & $\% 44.83$ & نسبة السيولة القانونية \\
\hline
\end{tabular}


بالنظر لنسبة السيولة القانونية نجد أن مستوى السيولة عرف ارتفاعا كبير ا خاصة في السنتين:

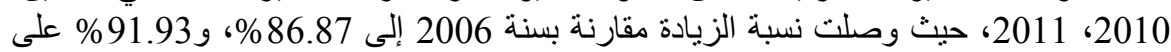

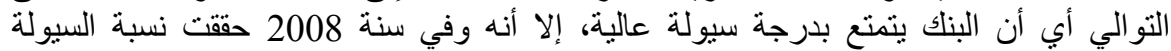

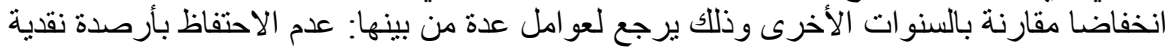
سائلة بنسبة كبيرة وتو جيه المو ارد المالية نحو المعاملات من أجل زيادة لئل نسبة الربحية. و عموما يمكن القول أن بنك البركة الجزائري حريص على توفير السيولة، حتى يضمن عدم

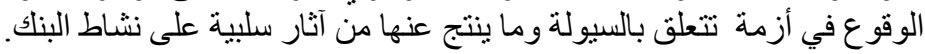

نسب الربحية: تعبر نسب الربحية عن مدى كفاءة البنك الإسلامي من خلال استغلال موارده

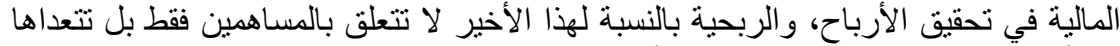

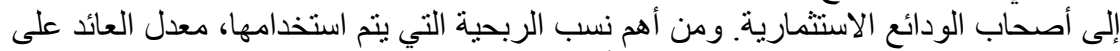

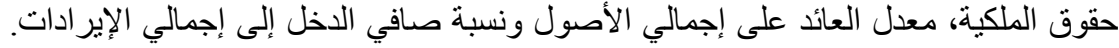
ويتم حسابها بنطبيق العلاقات الآتية(25)

$$
\text { معدل العائد على حقوق الملكية= صافي الدخل /حقوق الملكية }
$$

نسبة صافي الدخل إلى إجمالي الإيرادات(هامش الربح)= صافي الدخل /إجمالي الإير ادات

ويمكن إبراز نسب الربحية لبنك البركة الجزائري من خلال الجدول رقم(4)

\begin{tabular}{|c|c|c|c|c|c|}
\hline 2011 & 2010 & 2009 & 2008 & $200 \%$ & البيان \\
\hline$\% 18.38$ & $\% 17.21$ & $\% 21.21$ & $\% 41.65$ & $\% 27$ & معدل العائد على حقوق الملكية \\
\hline$\% 2.84$ & $\% 2.69$ & $\% 2.90$ & $\% 3.69$ & $\% 2.25$ & معدل العائد على إجمالي الأصول \\
\hline$\% 24.31$ & $\% 23.76$ & $\% 22.63$ & $\% 24.49$ & $\% 14.7$ & الإيرادات $\quad$ الصنتية $\quad$ إلىمالي \\
\hline
\end{tabular}

الجدول رقم (4):نسب الربحية لبنك البركة الجز ائري خلال 2011/2006

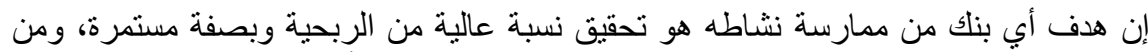

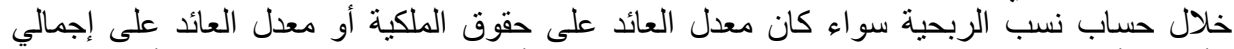

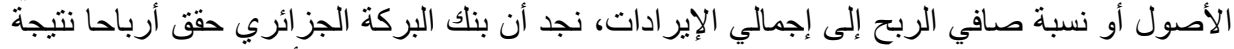

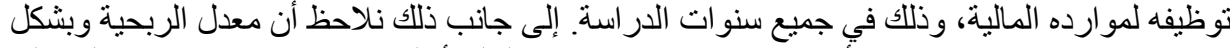

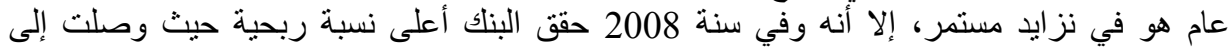

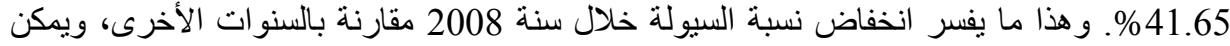

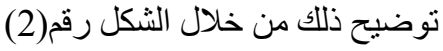


الثكل رقم (2): الوضع المالي للبنك من حيث مستوى الربحية والسيولة(\%)

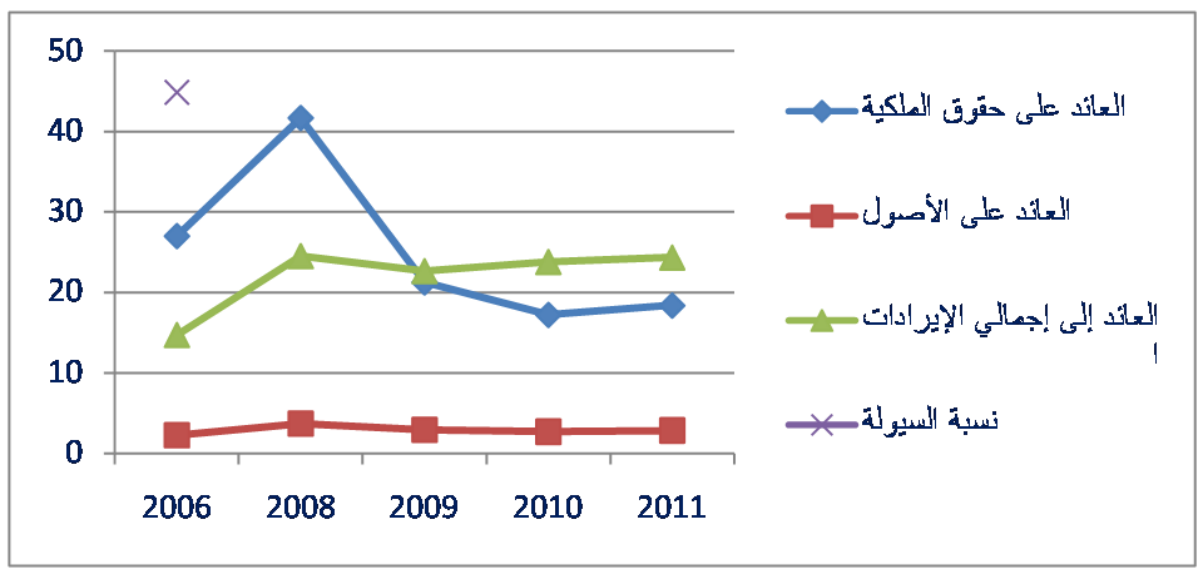

المصدر :من إعداد الباحثات بالاعتماد على الجدول رقم(4)

من خلال هذا الرسم البياني نلاحظ أن أعلى نسبة ربحية حققها البنك كانت في سنة 2008، وفي الدقابل

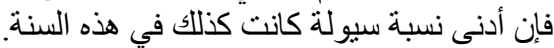

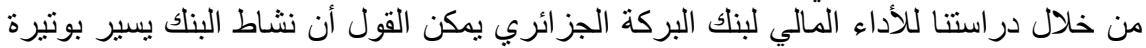

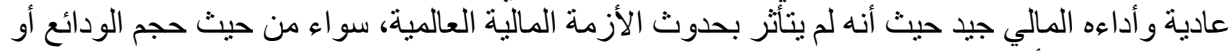

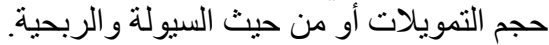
المطلب الثاني: تقييم الأداء المالي للبنتك الأردني الإسلامي

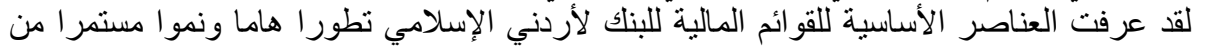

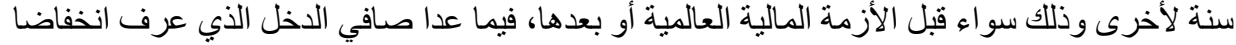
خلال سنة 2009، ويمكن إبراز ذللك من خلال الجدول(5).

الجدول رقم (5):بيان لأهم المعلومات المالية للبنك الأردني الإسلامي خلال 2011/2006

\begin{tabular}{|c|c|c|c|c|c|c|}
\hline 2011 & 2010 & 2009 & 2008 & 2007 & 2006 & البيان \\
\hline 3150 & 2881 & 2472 & 2170 & 1927 & 1726 & جموع الأصول \\
\hline 207 & 194 & 177 & 161 & 134 & 115 & حقوق الملكية \\
\hline 2858 & 2593 & 2188 & 1882 & 1677 & 1526 & حجم الودائع \\
\hline 1779 & 1696 & 1551 & 1406 & 1224 & 1028 & حجم التمويلات \\
\hline 28 & 29 & 28 & 35 & 23 & 16 & صافي الدخل \\
\hline
\end{tabular}


دراسة تقييميه لأثر الأزمة المالية العالمية على أداء البنوك الإسلامية

حالة بنك البركة الجزائري والبنك الأردني الإسلامي (2006-2011)

ويمكن إبراز التطورات الحاصلة في العناصر السابقة الذكر من خلال الرسم البياني رقم(3). الشكل رقم(3):بيان لتطور الأرقام المالية الهامة للبنك الأردني الإستلامي

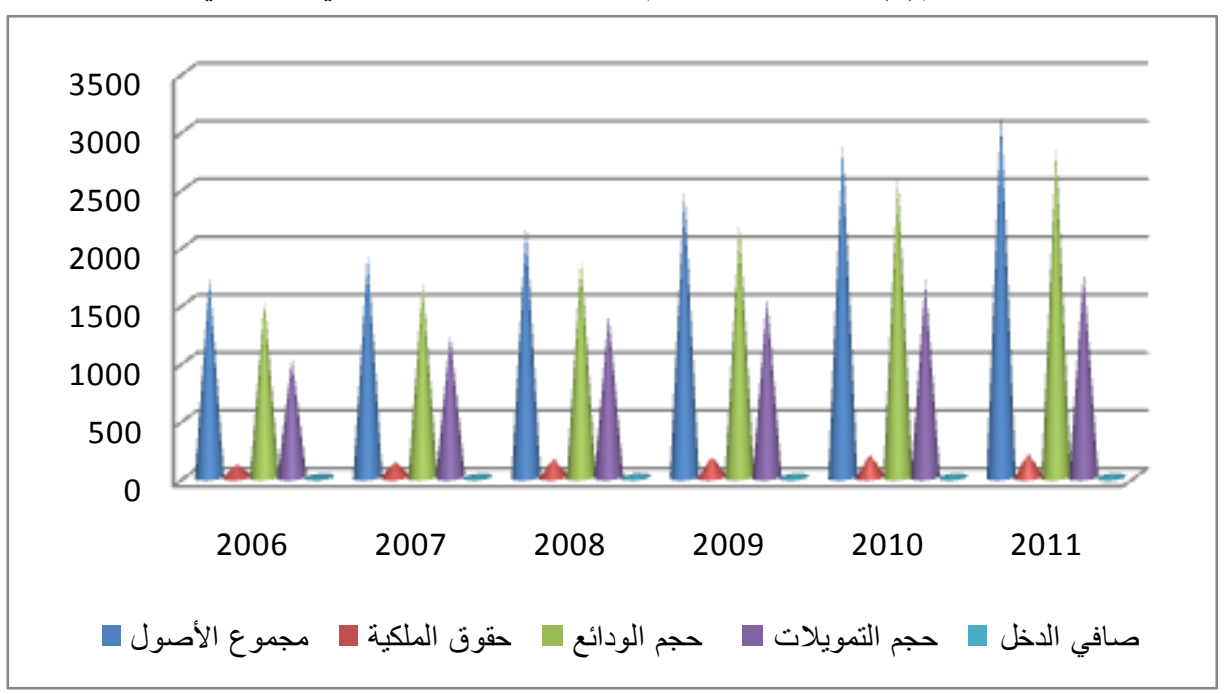

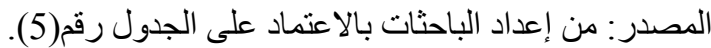

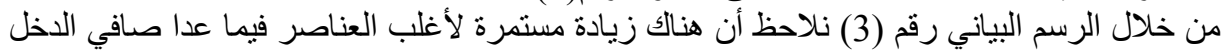

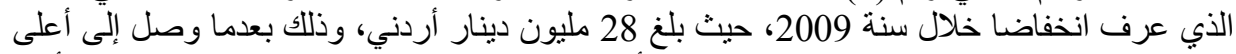

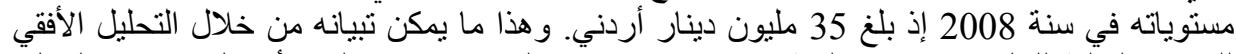

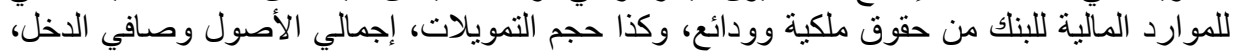
باعتماد سنة السة 2006 كسنة أساس. 
أ.د. زليخة بنحناشي/د. صونية عابد /سكينة غواس

الجدول رقم (6):التحليل الأفقي لأهم المعلومات المالية للبنك الأردني الإسلامي خلال 2006 2007/2006

\begin{tabular}{|c|c|c|c|c|c|c|}
\hline 2011 & 2010 & 2009 & 2008 & 2007 & (مليون دينار) & البيان \\
\hline$\% 82.50$ & $\% 66.92$ & $\% 43.22$ & $\% 25.72$ & $\% 11.65$ & 1726 & مجموع الأصول \\
\hline$\% 80$ & $\% 68.69$ & $\% 53.91$ & $\% 40$ & $\% 16.52$ & 115 & حقوق المطكية \\
\hline$\% 87.28$ & $\% 69.92$ & $\% 43.38$ & $\% 23.32$ & $\% 9.89$ & 1526 & حجم الودائع \\
\hline$\% 73.05$ & $\% 64.98$ & $\% 50.88$ & $\% 36.77$ & $\% 19.07$ & 1028 & حجم التمويلات \\
\hline$\% 75$ & $\% 81.25$ & $\% 75$ & $\% 118.75$ & $\% 43.75$ & 16 & صافي الدخل \\
\hline
\end{tabular}

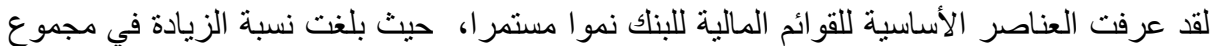

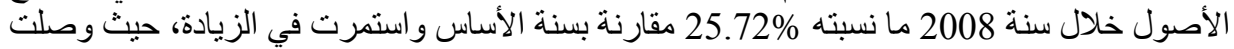

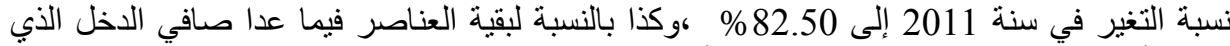
عرف أعلى ارتفاعا له خلال سنة حدوث الأزمة المالية العالمية، عيث بلغية العت نسبة الزيادة

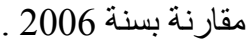

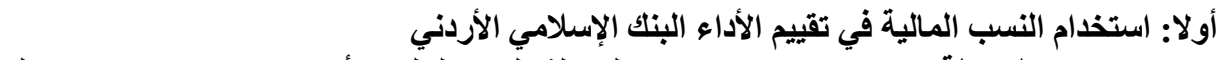

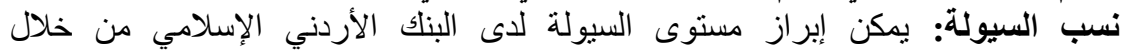

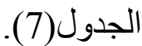

الجدول رقم (7): مستوى السيولة لدى البنأك الإسلامي الأردني خلال 2007 2008

\begin{tabular}{|c|c|c|c|c|c|}
\hline 2011 & 2010 & 2009 & 2008 & 2007 & البيان \\
\hline$\% 46.67$ & $\% 43.34$ & $\% 40.13$ & $\% 36.66$ & $\% 38.34$ & نسبة السيولة القانونية \\
\hline
\end{tabular}

ما يلاحظ على السيولة لاى البنك الأردني الإسلامي أنها عرفت انخفاضا في سنة 2008، حيث وصلت التها إلى 36.66\%، ولكن ابتداء من سنة 2009 بدأت في الارتفاع المستمر ووصلت خلال سنة الأنة 2011 إلى

نسب الربحية: إضافة لمستوى السيولة بمكن معرفة ربحية البنك الأردني الإسلامي من خلال

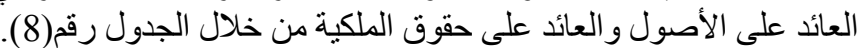


الجدول رقم (8): نسب الربحية للبنك الأردني الإسلامي خلال 2011/2006

\begin{tabular}{|c|c|c|c|c|c|c|}
\hline 2011 & 2010 & 2009 & 2008 & 2007 & 2006 & البيان \\
\hline$\% 0.9$ & $\% 1$ & $\% 1.13$ & $\% 1.61$ & $\% 1.19$ & $\% 0.93$ & العائد على الأصول \\
\hline$\% 13.53$ & $\% 14.95$ & $\% 15.82$ & $\% 21.74$ & $\% 17.16$ & $\% 13.91$ & الملكية ب على حقوق \\
\hline
\end{tabular}

المصدر: من إعداد الباحثات بالاعتماد على التقارير السنوية للبنك الأردني الإسلامي

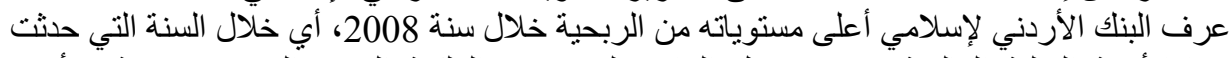

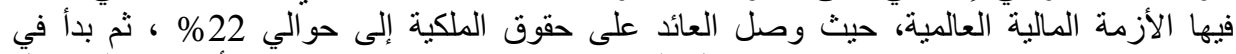
الانخفاض ابتداء من سنة 2009 حتى وصل إلى 13.53 \% في سنة 2011 فئل 2011 وهو أدنى حد لله خلال

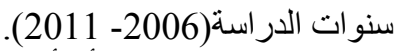

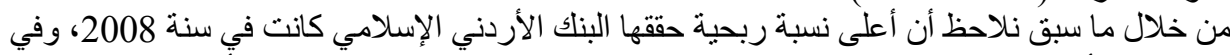
الدقابل فإن أدنى نسبة سيولة كانت كذللك في هذه رالسنة. هذان هذا ما هو موضح في الإسي الثكل أدناه.

الثكل رقم(4): الوضع المالي للبنك من حيث مستوى الربحية والسيولة(\%)

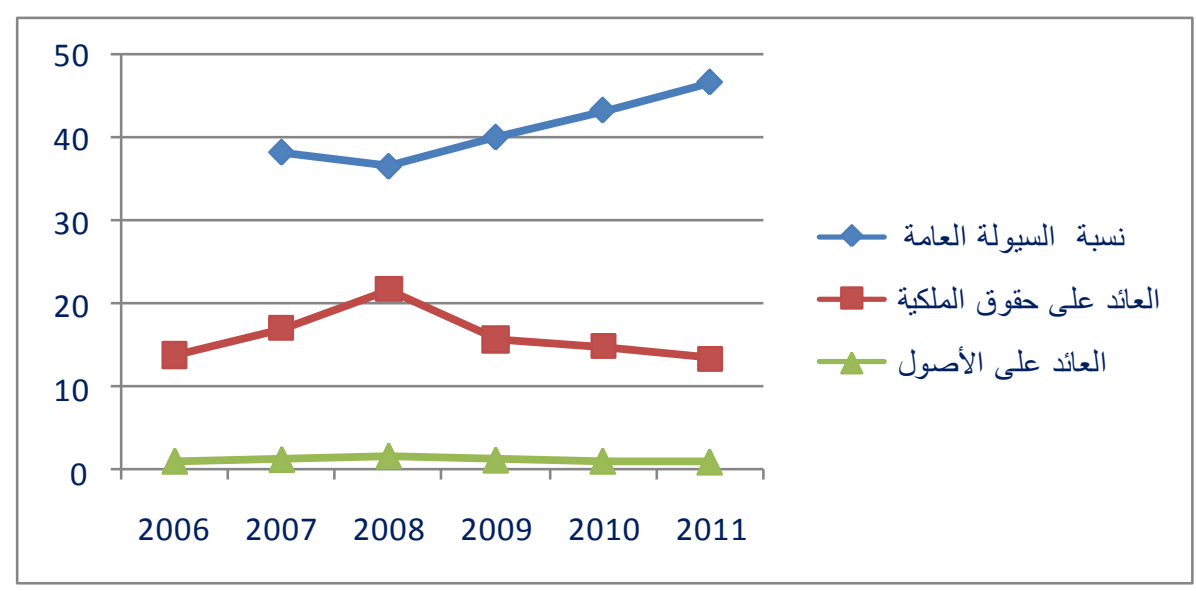

المصدر: من إعداد الباحثات بالاعتماد على الجدول رقم(8)

و الملاحظ على أداء البنك الأردني الإسلامي أن هناك زيادة في مستوى السيولة وانخفاضا في

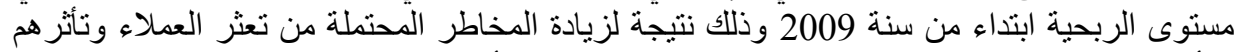

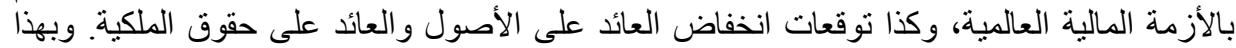
فإن تأثير الأزمة المالية العالمية على البنك الأردني الإسلامي كان طفيفا.

و عموما يمكن القول أن بنك البركة الجزائري لم يتأثر بالأزمة المالية العالمية وأن تألثأثر البنك الأردني

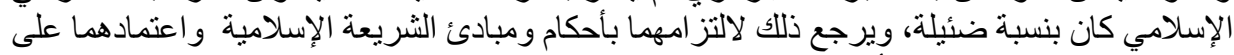

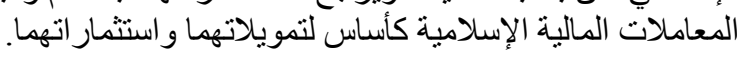


من خلال تحليلنا ومناقتشتا للأسباب المباشرة وغير المباشرة للأزمة المالية العالمية، وتركيزنا على هذه

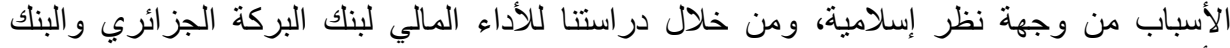
الأردني الإسلامي توصلنا إلى النتائج التالية :

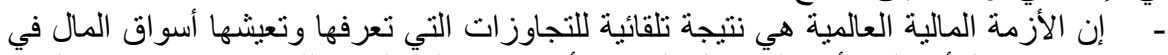

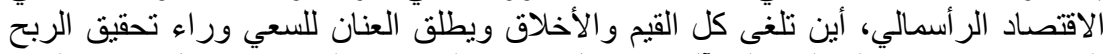

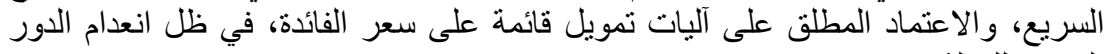

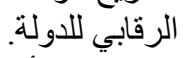

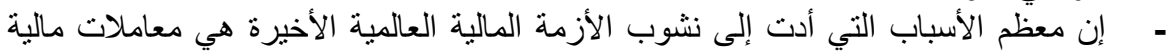

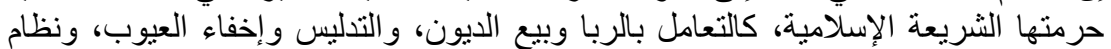

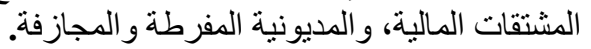

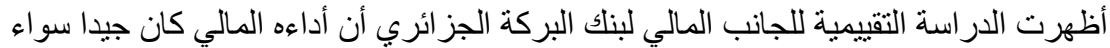
من حيث السيولة والربحية أو باقي المؤشرات المالية، وأنه لم يتأثر بحدوث الئر الأزمة المالية

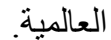
على الرغم من النتائج الجيدة التي حققها بنك البركة الجزائري، إلا أن حصته في السوق

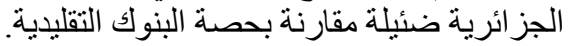

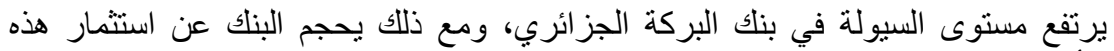

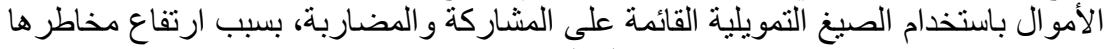

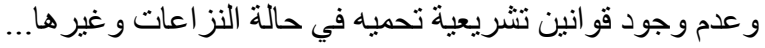

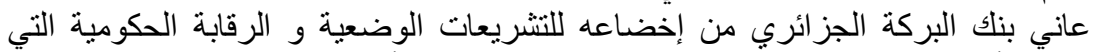

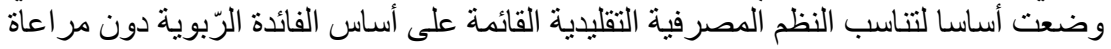

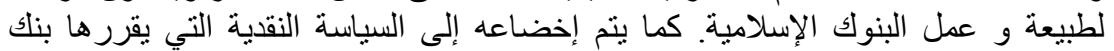

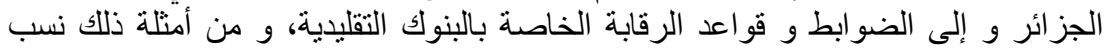

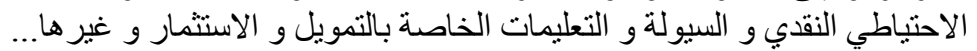

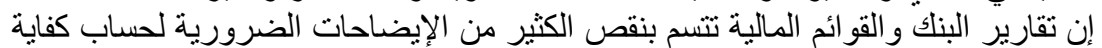

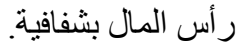
أما البنك الأردني الإسلامي فتأثره بالأزمة المالية العالمية كان خفيفا.

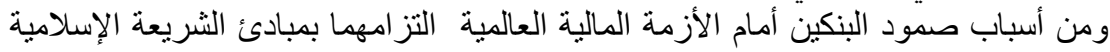

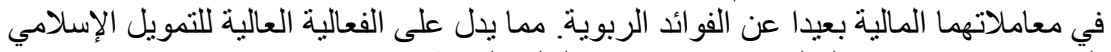

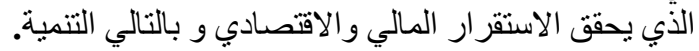

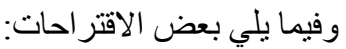
- ضرورة نوفير البيئة الملائمة والتشريعات القانونية و التنظيمية لعمل البنك الإسلامي في

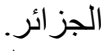
- ينبغي على البنوك الإسلامية الإفصاح عن البيانات وطريقة عرض القو ائم المالية للجمهور، وكذللك للباحثين لتسهيل عملهم.

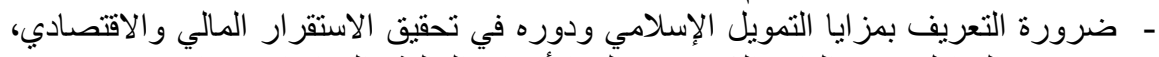

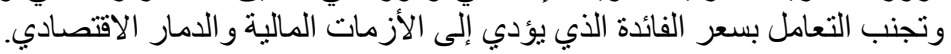

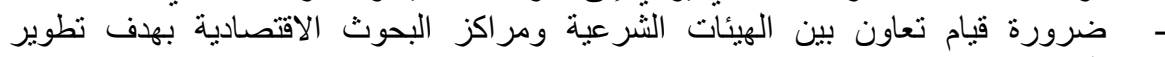

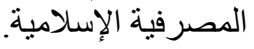
- - تعزيز الموارد البشرية وتأهيلها للإشراف على مختلف العمليات في البنوك الإسلامية. 


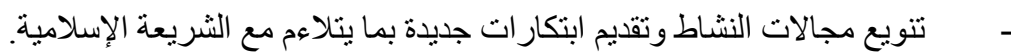

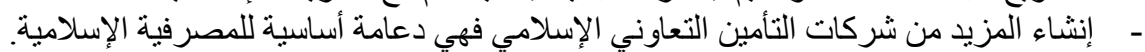

$$
\text { القرآن الكريم (سورة البقرة) }
$$

Clerc, Jan-Phillip, La crise des Subprimes ; Génie des Galaciers.2009, p22-(1)

Op Cit ,p $24-(2)$

$$
\text { (3)-عبد الخالق السعيد، التوريق المصرفي، بحث منشور في الموقع : البو ابة }
$$

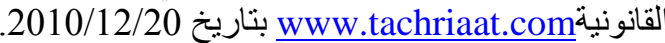

Randall Dodd et Paul Mills, crise hypothécaire : effet de contagion, -(4) finance et développement, magazine trimestriel du FMI, vol 45, n 2, Juin 2008

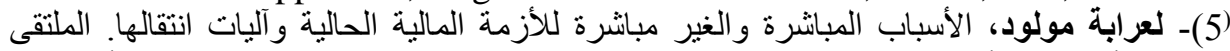

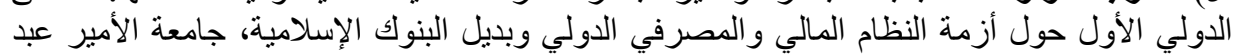

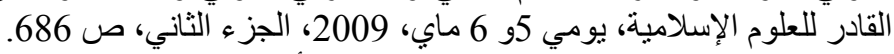

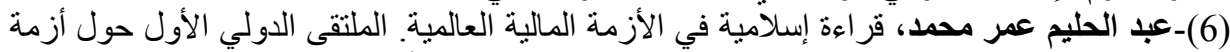

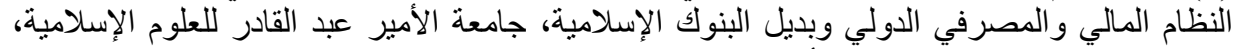

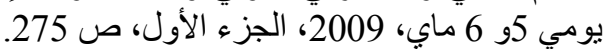

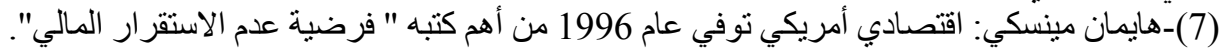

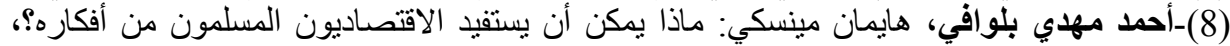

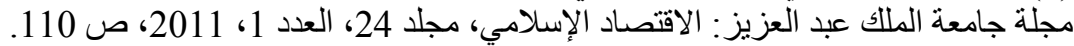

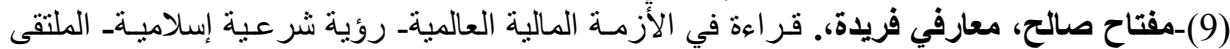

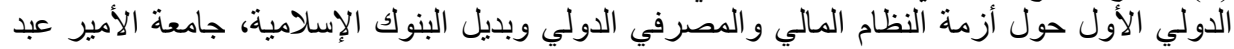

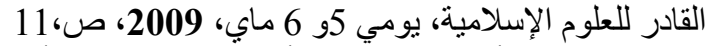

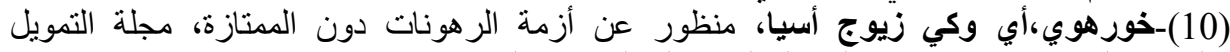

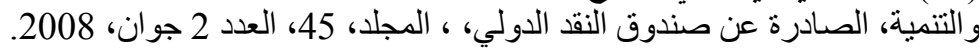
(11)-مجمع الفقه الإسلامي، قرار المجمع التابع لرابطة العالم الإسلامي في دورنه السادسة عشر المنعقدة بمكة المكرمة في يناير الإنير 2002. (12)-مجمع الفقه الإسلامي، قراريكئ المجمع التابع لمنظمة المؤتمر الإسلامي رقم 65/1/7 في دورته السابعة (1992) (19) (13) (13)-قارة م ، دحدح ،بدوي أ ، الأزمة المالية العالمية وتحديات استعادة الاستقرار الاقتصادي وتحقيق

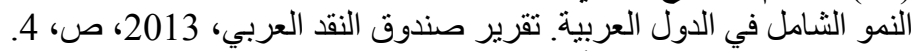

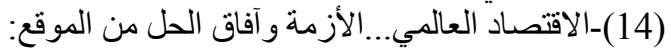

2011/10/26 بتاريخ /http://studies.aljazeera.net/ar/reports

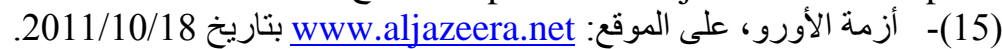
Banque de France,. La crise de la dette souveraine. Documents et Débats, -(16) mai 2012,p, 22

$$
\begin{aligned}
& \text { (17)-الاقتصاد العالمي...الأزمة وآفاق الحل، مرجع سابق. }
\end{aligned}
$$

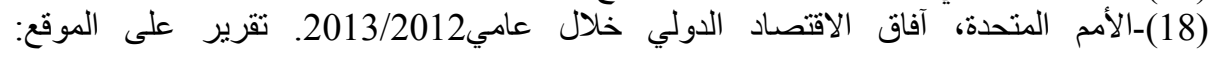

$$
\begin{aligned}
& \text { www.un.org }
\end{aligned}
$$

Perspectives économiques de l'OCDE, n 90, 2011, p, 615-(19)

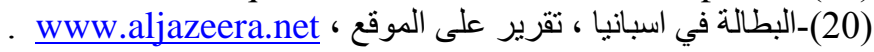

Perspectives économiques OCDE ,op ,cit,p,61 -(21) 
(22)-عبد الله شحاتة ، الأزمة المالية: المفهوم والأسباب، مقال منشور بالموقع: بـأريخ

2009/01/12 بناريخ ، بwww.isegs.com/forum/showthread.php?t=2335

(23)-التقارير السنوية لبنك البركة الجزائري للسنوات 2006، 2008، 2009، 2010، 2011 على

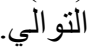

(24)-رضا صاحب أبو حمد، إدارة المصارف: مدخل تحليلي كمي معاصر، دار الفكر للطباعة والنشر

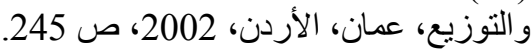

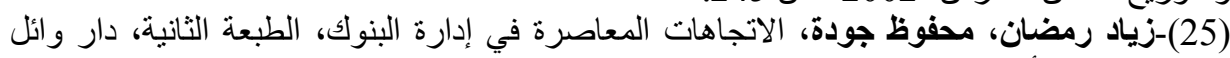

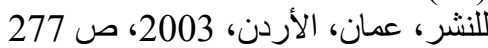

(26)-التقارير السنوية للبنك الأردني الإسلامي للسنوات 2007،2006، 2008، 2008، 2009، 2010،

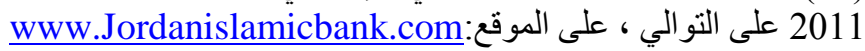

